\title{
Recursion to food plants by free-ranging Bornean elephant
}

Megan English, Graeme Gillespie, Benoit Goossens, Sulaiman Ismail, Marc Ancrenaz, Wayne Linklater

Plant recovery rates after herbivory are thought to be a key factor driving recursion by herbivores to sites and plants to optimise resource-use but have not been investigated as an explanation for recursion in large herbivores. We investigated the relationship between plant recovery and recursion by elephants (Elephas maximus borneensis) in the Lower Kinabatangan Wildlife Sanctuary, Sabah. We identified 182 recently eaten food plants, from 30 species, along $14 \times 50 \mathrm{~m}$ transects and measured their recovery growth each month over nine months or until they were re-browsed by elephants. The monthly growth in leaf and branch or shoot length for each plant was used to calculate the time required (months) for each species to recover to its pre-eaten length. Elephant returned to all but two transects with 10 eaten plants and 26 plants died leaving 146 plants that could be reeaten. Recursion occurred to $58 \%$ of all plants and 12 of the 30 species. Seventy-seven percent of the re-eaten plants were grasses. Recovery times to all plants varied from two to twenty months depending on the species. Recursion to all grasses coincided with plant recovery whereas recursion to most browsed plants occurred four to twelve months before they had recovered to their previous length. The small sample size of many browsed plants that received recursion and uneven plant species distribution across transects limits our ability to generalise for most browsed species but a prominent pattern in plant-scale recursion did emerge. Plant recovery time was a good predictor of time to recursion but varied as a function of growth form (grass, ginger, palm, liana and woody) and differences between sites. Time to plant recursion coincided with plant recovery time for the elephant's preferred food, grasses, and perhaps also gingers, but not the other browsed species. Elephants are bulk feeders so it is likely that they time their returns to bulk feed on these grass species when quantities have recovered sufficiently to meet their intake requirements. The implications for habitat and elephant management are discussed. 
3 Recursion to food plants by free-ranging Bornean elephant

4

5 Authors: Megan English ${ }^{1}$, Graeme Gillespie ${ }^{2}$, Benoit Goossens ${ }^{3,4,5}$, Sulaiman Ismail ${ }^{6}$, Marc

6 Ancrenaz $^{6}$ and Wayne Linklater ${ }^{1,7}$.

$7 \quad{ }^{1}$ Centre for Biodiversity and Restoration Ecology, School of Biological Sciences, New Kirk Building, Kelburn

8 Parade, Kelburn Campus, Victoria University of Wellington, New Zealand, 6012

9 Corresponding author: Megan English

10 (megs.english@gmail.com Ph:+61 265686903)

11

${ }^{2}$ Zoology Department, University of Melbourne, Parkville, Victoria, 3010, Australia

${ }^{3}$ Danau Girang Field Centre, c/o Sabah Wildlife Department, Wisma Muis, 88100 Kota Kinabalu, Sabah, Malaysia

${ }^{4}$ Organisms and Environment Division, School of Biosciences, Cardiff University, Sir Martin Evans Building, Museum Avenue, Cardiff CF10 3AX, UK

${ }^{5}$ Sabah Wildlife Department, Wisma Muis, 88100 Kota Kinabalu, Sabah, Malaysia

${ }^{6}$ HUTAN Elephant Conservation Unit and Kinabatangan Orangutan Conservation Project, Sukau, Kinabatangan, Sabah, Malaysia

${ }^{7}$ Centre for African Conservation Ecology, Nelson Mandela Metropolitan University, Port Elizabeth, South Africa 


\section{Introduction}

Recursion by wild herbivores is the repeated use of the same sites or finer-scale reuse of resources, such as individual plants, within a site over time. Importantly, recursion by wild herbivores to previously browsed or grazed sites and plants is thought to facilitate plant productivity (re-growth) and its consumption at stages of highest productivity (McNaughton, 1985; Gordon \& Lindsay, 1990; English et al., 2014a). Recursion may also accelerate nutrient cycling at sites (Gordon \& Lindsay, 1990, McNaughton et al., 1997) and so maintain them as nutrient hotspots (Winnie et al., 2008). Thus, recursion is thought to trigger and maintain the positive feedback between large herbivore feeding, and vegetation regeneration and palatability (McNaughton et al., 1997). Although recursion is consistent in these ways with optimal-foraging theory and strategies, and assumed to be ubiquitous (McNaughton, 1985), it has only rarely and recently been investigated amongst wild herbivores.

Recursion has been described at site and landscape scales for wild buffalo (Syncerus caffer; Bar-David et al., 2009; Benhamou \& Riotte-Lambert, 2012) and impala (Aepyceros melampus; Riotte-Lambert et al., 2013) but finer-scale recursion to individual plants has not been investigated. Nevertheless, recursion has been explored amongst nectivorous insects and birds where the reuse of individual plants was found to occur after nectar replenishment (Davies \& Houston, 1981; Bell, 1990; Williams \& Thomson, 1998). Recursion behaviour has also been described in frugivorous primates returning to the same trees for fruit (Garber, 1988; Garber \& Jelinik, 2006; Erhart \& Overdorff, 2008; Janmaat et al., 2013; Porter \& Garber, 2013). As for nectar and fruit feeders, plant recovery period is also expected to strongly influence the movements and recursion frequency (rate) of grazers and browsers amongst sites. Prior to this study, the expected correspondence between individual plant recovery and recursion by wild grazers or browsers and, therefore, as an explanation for site recursion has not been explored.

Studies of recursion have important implications for animal population and habitat management (Bar-David et al., 2009). Most evaluations of wild animal resource requirements and preferences are based largely on the premise that if animals use resources (e.g., sites or food species) in lower or higher proportion to their availability then this suggests that the resource is avoided or preferred, respectively (Johnson, 1980). This framework is most commonly applied in studies that occur over relatively short time-frames to provide an indicative 'snap-shot' of 
resource-use. However, in natural environments resources are not consistently available in distribution, proportion and density through time and animals may reuse some resources but not others. An uncommon species of food-plant, for example, may appear to be a minor or unimportant part of the diet at selected sites but might be the subject of repeated use such that recursion would illustrate it to be highly selected. Alternatively, a common species of food-plant may appear to be avoided until investigation of recursion reveals reuse. Thus, studies of recursion are necessary to elaborate on spatial variation in availability and selection when assessing food and habitat preferences.

Recursion patterns may also be a useful indicator of population relations with habitat.

Large herbivores, like elephants, are a particularly interesting species in which to study recursion as they are ecosystem engineers - having complex, scale-dependent effects on habitat structure and vegetative community (Bond, 1993; Jones et al., 1996). A study of recursion at the individual plant scale can identify if elephants are potentially over-utilising and depleting resources by re-browsing plants before they have recovered, or if they are facilitating growth of preferred or bulk-food plants. Thus, increases in rates of recursion that exceed plant recovery rates could indicate that a population exceeds habitat capacity and reveal how they are influencing vegetation community structure and composition. Alternatively, plant recovery rates that exceed recursion may be evidence of further capacity to support greater elephant densities. An understanding of recursion patterns, therefore, may augment evaluations of a habitats capacity to support elephant and vegetation dynamics on the landscape under elephant grazing and browsing regimes.

In a previous study, English et al. (2014a) showed patterns of elephant recursion to sites consistent with site quality and optimal foraging theory. In this study we aim to test the hypothesis that recursion by elephants to sites in tropical rainforest also involves recursion to individual plants and corresponds with their plant recovery. We predict that elephant recursion would coincide with plant recovery and help to explain the periodicity of site recursion observed previously.

\section{Materials and Methods}

Study site and focal species 
The dominant landform of the Lower Kinabatangan region is the extensive floodplain and its swamps. Soils are predominantly alluvial and derived from sedimentary deposits often rich in magnesium. Beyond the floodplains, soils are derived from sedimentary rocks (Azmi, 1998). The Kinabatangan floodplain is characterized by a warm, wet and humid tropical climate. The larger temperature variations are diurnal rather than seasonal. Mean monthly temperatures range between $21^{\circ} \mathrm{C}$ and $34^{\circ} \mathrm{C}$ (Ancrenaz et al., 2004). The north-easterly monsoon brings high monthly rainfall from October to February, although rainfall is also common from March to September. Dry months, with mean monthly rainfall $<60 \mathrm{~mm}$ tend to occur at roughly 3 -year intervals. The mean annual rainfall is $3000 \mathrm{~mm}$ (Acres \& Folland, 1975).

This study focused on the area between the villages of Abai and Batu Puteh $\left(5^{\circ} 18^{\prime}-\mathrm{N} 5^{\circ}\right.$ $\left.42^{\prime}-\mathrm{N}, 117 \circ 54^{\prime}-\mathrm{E} 118^{\circ} 33^{\prime}-\mathrm{E}\right)$, which were the downriver and upriver limits of the Lower Kinabatangan Wildlife Sanctuary (LKWS) elephant population's range (approximately 200 individuals). The study area (approximately $218 \mathrm{~km}^{2}$ ) contains seven sections, each section referred to as a 'lot', including $89 \mathrm{~km}^{2}$ of protected forest reserves (Estes et al., 2012). The elephant herds utilised their whole range throughout the year including use of privately owned forests and cultivated land, particularly oil palm plantations that were adjacent to and between forested areas. Elephants in LKWS are mostly restricted to the linear fragments of forest along the Kinabatangan River (Estes et al., 2012) (Fig 1).

\section{Plant recursion}

Fourteen $50 \mathrm{~m}$ transects were located where elephants had fed previously. Transects were $>$ $300 \mathrm{~m}$ apart. One transect was established per day. We tracked fresh elephant signs including footprints, dung and signs of feeding to establish the transect along the group's feeding path. All plants showing signs of elephant feeding within $2 \mathrm{~m}$ either side of transect were marked and labelled with the date and a reference number. Samples of all plant species were collected for identification at the Sabah Forestry Department Herbarium (SAN), Sandakan. The growth and recovery of each plant after herbivory was measured each month from April to December 2011 or until the elephants re-browsed the plant's new growth. The length of the plant stem prior to browsing or grazing was determined by measuring the length of stems of the same plant that were not eaten, or remnants of the eaten stem, as a surrogate reference of original stem length. If the plant died or the new growth was re-browsed by other herbivores, thus preventing 
measurements of regrowth, this was recorded. It was possible to differentiate between elephant feeding signs and other herbivore feeding signs, such as from bearded pig (Sus barbatus) and sambar Deer (Rusa unicolor), because of the other sign and spoor left in the area, such as dung, footprints, the way in which the plant was eaten and the height of the sign. Recorded GPS positions of two collared elephants from the two main herds in LKWS confirmed when the focal group returned to the site and transect within the month and the age of the feeding signs allowed approximation of whether this coincided with the time of the focal elephant herds visit. If food plants had been re-browsed by elephant, but the focal group had not returned within the month, this was not recorded as a recursion.

Plant physiognomy varies among species and between plants within a species. Regrowth measurements were taken on a selected new shoot closest to the growth node nearest the feeding sign, or from the plant base, depending on plant physiognomy and how it recovered (see Fig 2 for typological examples). Measurements included new shoot growth in length and basal diameter, and a count of the number of new shoots produced each month. The approximate length and the basal diameter of the original feeding sign on each plant were compared to the length and basal diameter of the new growth when it was fed on again. If we returned to a plant and it had been fed on since the last measurement was taken, the growth measurements from the prior month were used for comparison. The same technique was used for the two grasses:

Phragmites karka - a reed, and Dinochloa scabrida - a bamboo, as their structure is a main stem with new growth emerging from nodes along the main stem, or from the root system. Short grasses were not included due to difficulty in identifying feeding signs (i.e. the whole plant is often ingested) and measuring recovery growth related to feeding by elephants. Student's T-tests were used to compare the lengths of the individual plant new growth with their lengths when first selected for feeding to determine any significant difference.

\section{Plant recovery growth and recursion rate}

The expected time required for each individual plant to recover was estimated by averaging the monthly growth in length $(\mathrm{mm})$ of the plant, divided by its estimated length at the beginning of study which was based on what remained of the stem after elephant feeding and other stems on the same plant as a surrogate reference. Based on this monthly growth average, we estimated how many months it would take for the individual plant to return to its previous length. The 
161

162

163

164

\section{5}

166

167

168

169

170

171

172

173

174

175

176

177

178

179

180

181

182

183

184

185

186

187

188

189

190

191

difference in the average recovery time (months) subtracted from the average recursion time (months) is shown for each growth form (grass, ginger, palm, liana and woody species) where the plant species are the replicates used to derive standard errors for each growth form.

\section{Multi-model inference and selection}

An information theoretic approach (linear mixed effects model) was applied to test the hypothesis for recursion time and plant recovery time. Individual plant recovery times and time to recursion were used in the statistical analysis. We predicted recursion would occur after individual plants had recovered to their pre-herbivory height. We evaluated the power of plant recovery to explain recursion in the absence of other a priori hypotheses by comparing a model of our hypothesis with models that included random effects for site (transect) and growth form. We described and evaluated models in the 'Ime4' package in R (Bates et al. 2014). All plants browsed by elephants, including those plants that did not receive recursion but were located on transects that received recursion, were included in the analyses. We used maximum likelihood (MLE) to provide estimates of the model's parameters because fixed effects were different between models.

\section{Results}

Individual food plants, recently eaten by elephant, were identified by following the herd that was allowed to select sites and plants without influence. As one would expect for a herbivore selecting from a diverse landscape and flora we identified many individuals of commonly eaten species but a larger number of species represented by a few individuals. Thus, our sampling is skewed towards a few commonly eaten plants with many other species being eaten little by elephant and sampled less.

We recorded a total of 182 plants from 30 species eaten by elephants over 14 transects. Eighty-six of these plants from 12 species were re-browsed, i.e. recursion to individual plants (Fig 3a). Twenty-six plants died and did not recover after being partially eaten by elephants and were, therefore, not included in further analyses (Fig 3b). Two transects were not returned to by the elephants (five plants each transect), resulting in 146 plants used for recursion analyses.

The time to recursion for each plant species varied across the nine months of sampling (Table 1). Four species including ginger: Costus speciousus, grasses: Dinochloa scabrida, 
192 Phragmites karka and liana: Spatholobus sp., had recovered to their previous size when they

193 were re-browsed, whereas the remaining eight species were re-browsed before they had fully 194 recovered (Fig 4 and 5). Seventy-seven percent of re-browsed plants were grasses. A linear 195 mixed-effects model found that the plant recovery time is a good predictor of time to recursion 196 but this varies as a function of growth form (grass, ginger, palm, liana and woody) and 197 differences between sites. A large amount of variation is unexplained by recovery time (Table 198 2).

199 Two species of grass, Phragmites karka - a reed, and Dinochloa scabrida - a bamboo,

200 received recursion at a time when their length was not significantly different from when they had

201 first been selected (Reed: t-test, $\mathrm{df}=50, P=0.137$; Bamboo: $\mathrm{t}$-test, $\mathrm{df}=17, P=0.232$ ) (Fig 4).

202 However all other growth forms that were selected were re-browsed before they had recovered to 203 their previous length except one ginger species, Costus speciousus, and one liana species, 204 Spatholobus sp. Mean recursion time subtracted from mean recovery time to all growth forms 205 illustrates that recursion to palms, lianas and woody species occurred many months before the 206 individual plants had recovered (Table 1 and Fig 5)

207

\section{Discussion}

210 Plant recovery time after herbivory as an explanation for site and plant recursion is expected

211 from optimal foraging theory and has been postulated for large wild herbivores (e.g., Bar-David

212 et al., 2009) but has not yet been investigated in uncontrolled environments. We found plant

213 recovery time to be a good predictor of time to plant recursion by elephant but also observed

214 large variation with differences in growth form and amongst sites. The recovery time of the two

215 primary species of grass - elephants' primary food species - coincided with plant and site

216 recursion but this was not also true for browsed species. Palms, lianas and woody species were

217 re-browsed before they had recovered. The large amount of variation attributable to sites may

218 pertain to a number of abiotic influences on plant recovery rates such as soil fertility and micro-

219 climate.

220 Recursion rate corresponded best with the recovery of grasses: Dinochloa scabrida and

221 Phragmites karka, even though those grass species had very different recovery times: e.g., 2-3

222 and 4-5 months, respectively. In all cases these grazed plants were returned to after they had 
223

224

225

226

227

228

229

230

231

232

233

234

235

236

237

238

239

240

241

242

243

244

245

246

247

248

249

250

251

252

253

recovered. Grasses have also been identified as the preferred food plants of the elephants (English et al., 2014b) and they made up 43\% of all plants selected and 77\% of plants receiving recursion. Elephants are bulk feeders so it is likely that they time their returns to bulk feed on grasses and grassed sites when stands have recovered sufficiently to meet their intake requirements. Grasses were less likely to die and faster to recover compared to other growth forms. Other than grasses, most species did not receive recursions, or if they did, it occurred before the individual plants had recovered.

Recursion to a few poorly regenerated species, specifically woody trees, palms, lianas and one species of ginger may be a result of elephants foraging on other nearby plants (i.e., grasses) and indiscriminately re-browsing those unrecovered plants. If this was the case we would expect the re-browsing of plants prior to their recovery would be most common when they are found within grass-dominated sites. Half of the browse plant samples found within grassdominated sites were re-browsed before their recovery compared to $20 \%$ of those outside grassed areas. Thus, premature woody-plant re-browsing could be an ancillary to grazing sites.

Alternatively, recursion to unrecovered plants may be due to elephants specifically targeting those growth forms or their younger growth because they contribute a small but important component of the diet (e.g., trace elements). Forest plant productivity and nutritional quality has been found to be highest after around 5-6 months of plant regrowth (Plumptre, 1993), which might explain why browsed plants were re-eaten before the recovery of their branch and stem lengths that takes longer. Furthermore, elephants may select some food plants not just to facilitate re-growth productivity but also to manipulate the structure and composition of the plant community at sites. For example, Jachman and Bell (1985) proposed that African elephants selectively fell preferred tree species to stimulate coppicing but also to increase the availability of other palatable forage species. Elephants may, therefore, alter structure and floristic composition, especially of woody species, in ways that increase rather than reduce carrying capacity. If woody plants are re-browsed faster than they can recover then elephant feeding might lead to the creation and maintenance of open, grassed areas. These areas are likely to become dominated by early successional species, thus providing the elephants with more of their preferred food such as grasses. Therefore, feeding on woody species faster than they can recover may augment grass patches and prevent woody invasion. This is a common observation of elephants. As ecosystem engineers they are known to alter the structure and composition of 
254 habitat and plant communities (Laws, 1970; Bryant, 1981; Bergström \& Danell, 1987; du Toit et 255 al., 1990; Ben-Shahar, 1993; Prins \& Olff, 1998). Elephant impact on woody vegetation has led 256 to decreasing numbers of trees and increase of open areas in Africa (Conybeare, 2004; O'Connor 257 et al., 2007). The results of our study suggest that elephants in LKWS may be controlling re258 forestation within open grass areas by re-browsing on woody species, lianas, and palms before 259 their recovery. However a long-term study on elephants as ecosystem engineers within the 260 Lower Kinabatangan is required.

261 Another plausible explanation for recursion on poorly regenerated plants is that these 262 plants are highly desirable and resources in the area are inadequate, perhaps due to spatial 263 constraints, habitat fragmentation and overstocking. Resources may be insufficient to support a 264 slower site recursion rate. Elephant feeding on plants before they have recovered might indicate 265 that food species are being over-exploited and that the elephant population is approaching or 266 exceeding habitat carrying capacity. However, with the exception of grasses, our results show that only 19 of 89 browse plants were returned to for feeding during the nine-month study period. This finding suggests that there is no evidence from recursion data that this elephant population has exceeded the area's carrying capacity. The two first explanations, individually or in combination, best explain the pattern.

Limitations in data collection in this study are imposed by the lack of independence between plant samples within species and amongst sites that were determined by elephant movements and choices but also due to plant distributions within the study area, particularly for

274 Poaceae, which occur in homogenous stands at just a few sites that are highly favoured by the elephant (English et al. 2014b). Sites and transects are not balanced replicates for each plant species measured, and recursion occurred to most but not all selected sites. A lack of equal distribution of all species across all transects due to elephant food plant choices and plant species heterogeneity and distribution influenced the strength of the data. Moreover, despite a satisfactory sample size of browsed plants initially, a lack of re-browsing to plant samples across a variety of species resulted in reduced sample sizes of plants receiving recursion, especially for woody species, and therefore limited statistical power.

Despite these limitations, we established the likely importance of recovery time for recursion of elephant's bulk food, grass. This was a novel approach for establishing the relationship between resource recovery and recursion by elephants in LKWS by measuring plant 
285

286

287

288

289

290

291

292

293

294

295

296

297

298

299

300

301

302

303

304

305

306

307

308

309

310

311

312

recovery rates in an uncontrolled environment. Our results recognised the importance of incorporating open land, for elephants to feed on grasses, into corridor design and reforestation programmes in the area. Future studies investigating recursion to plants could be improved by ensuring a relatively even distribution of plant samples across all transects, increasing sample sizes of each species, i.e. more transects or extending sampling distance ( $>2 \mathrm{~m}$ either side of transect) in order to incorporate a larger number of samples within each species for statistical comparison. It would also be beneficial to compare inter-annual variation in re-browsing and elephant impact on their resources as ecosystem engineers.

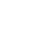

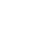

8

\section{References}

Acres BD, Folland CJ. 1975. The Soils of the Sabah: Sandakan and Kinabatangan Districts. Land Resources Division, Directorate of Overseas Surveys.

Ancrenaz M, Calaque R, Lackman-Ancrenaz I. 2004. Orangutan nesting behaviour in disturbed forest of Sabah, Malaysia: Implications for nest consensus. International Journal of Primatology 25: $983-1000$.

Azmi R. 1998. Natural Vegetation of the Kinabatangan Floodplain. Part 1: Background and Preliminary Checklist. Report. Kota Kinabalu, Sabah: WWF-Malaysia.

Bar-David S, Bar-David I, Cross PC, Ryan SJ, Knechtel CU, Getz WM. 2009. Methods for assessing movement path recursion with application to African buffalo in South Africa. Ecology 90: $2467-2479$. 
Bates D, Maechler M, Bolker B, Walker S. 2014. lme4: Linear mixed-effects models using

Eigen and S4. R package version 1.0-6. http://CRAN.R-project.org/package=lme4.

316

Bell W. 1990. Searching behaviour patterns in insects. Annual Review Entomology 35: 447-467.

318

Benhamou S, Riotte-Lambert L. 2012. Beyond the utilisation distribution: Identifying homerange areas that are intensively exploited or repeatedly visited. Ecological Modelling 227: 112-116.

322

Ben-Shahar R. 1993. Patterns of elephant damage to vegetation in northern Botswana. Biological Conservation 65: 249-256.

Bergström R, Danell K. 1987. Effects of simulated winter browsing by moose on morphology and biomass of two birch species. The Journal of Ecology 75: 533-544.

328

Bond WJ. 1993. Keystone species. In: Schulze, E.D., Mooney, H.A. (Eds.), Biodiversity and Ecosystem Function. Springer-Verlag, pp. 237-253.

331

332

Bryant JP. 1981. Phytochemical deterrence of snowshoe hare browsing by adventitious shoots of four Alaskan trees. Science 213: 889-890.

334

Conybeare AM. 2004. Elephant impacts on vegetation and other biodiversity in the broadleaved woodlands of S-Central Africa. Biodiversity of the Four Corners Area: Technical Reviews Zimbabwe. pp. 477-508.

Davies NB, Houston AI. 1981. Owners and satellites-the economics of territory defense in the 341 pied wagtail (Motacilla alba). Journal of Animal Ecology 50: 157-180. 
343

344

345

346

347

348

349

350

351

352

353

354

355

356

357

358

359

360

361

362

363

364

365

366

367

368

369

370

371 Jachman H, Bell RHV. 1985. Utilisation by elephants of the Brachystegia woodlands of the

372 Kasungu National Park, Malawi. African Journal of Ecology 23: 245-258.

English M, Ancrenaz M, Gillespie G, Goossens B, Nathan S, Linklater WL. 2014a. Foraging site recursion by forest elephants (Elephas maximus borneensis). Current Zoology 60: 551-559.

English M, Gillespie G, Ancrenaz M, Ismail S, Goossens B, Nathan S, Linklater WL. 2014b.

Plant selection and avoidance by the Bornean elephant (Elephas maximus borneensis) in tropical forest: does plant recovery rate after herbivory influence food choices? Journal of Tropical Ecology 30: 371-379.

Erhart EM, Overdorff DJ. (2008). Spatial memory during foraging in prosimian primates:

Propithecus edwardsi and Eulemur fulvus rufus. Folia Primatologica 79: 185-196.

Estes JG, Othman N, Ismail S, Ancrenaz M, Goossens B, Ambu LN, Palmiotto PA. 2012.

Quantity and configuration of available elephant habitat and related conservation concerns in the Lower Kinabatangan floodplain of Sabah, Malaysia. PloS one 7: e44601.

Garber PA. 1988. Foraging decisions during nectar feeding by tamarin monkeys (Saguinus mystax and Saguinus fuscicollis, Callitrichidae, Primates) in Amazonian Peru. Biotropica 20: $100-106$.

Garber PA, Jelinek PE. 2006. Travel patterns and spatial mapping in Nicaraguan mantled howler monkeys (Alouatta palliate). In: Estrada A, Garber PA, Pavelka MSM, Luecke Led. Springer US: New Perspectives in the Study of Mesoamerican Primates. pp. 287-309.

Gordon IJ, Lindsay KW. 1990. Could mammalian herbivores "manage" their own resources? Oikos 59: 270-280. 
373 Janmaat KR, Ban SD, Boesch C. 2013. Taï chimpanzees use botanical skills to discover fruit:

374 What we can learn from their mistakes. Animal Cognition 16: 851-860.

375

376 Johnson DH. 1980. The comparison of usage and availability for evaluating resource preference.

377 Ecology 61: 65-71.

378

379

Jones CG, Lawton JH, Shachak M. 1996. Organisms as ecosystem engineers. In Ecosystem Management. Springer New York. pp. 130-147.

381

382 383

Laws RM. 1970. Elephants as agents of habitat and landscape change in East Africa. Oikos 21: $1-15$.

384

385

386

McNaughton SJ. 1985. Ecology of a grazing ecosystem: The Serengeti. Ecological Monographs 55: 259-294.

387

388

389

McNaughton SJ, Banyikwa FF, McNaughton MM. 1997. Promotion of the cycling of dietenhancing nutrients by African grazers. Science 278: 1798-1800.

390

391

O’Connor TG, Goodman PS, Clegg B. 2007. A functional hypothesis of the threat of local

392 extirpation of woody plant species by elephant in Africa. Biological Conservation 136: 329-345.

393

394

395

Plumptre AJ. 1993. The effects of trampling damage by herbivores on the vegetation of the Parc 396

397 National des Volcans, Rwanda. African Journal of Ecology 32: 115-129.

398

Porter LM, Garber PA. 2013. Foraging and spatial memory in wild Weddell's saddleback

399 tamarins Saguinus fuscicollis weddelli when moving between distant and out-of-sight goals. International Journal of Primatology 34: 30-48.

400

401 Prins HHT, Olff H, Newbery DM, Brown ND. 1998. Species-richness of African grazer

402 assemblages: towards a functional explanation. In Dynamics of tropical communities: the 37th 
403 symposium of the British Ecological Society, Cambridge University, 1996. (pp. 449-490).

404 Blackwell Science Ltd.

405

406 Price PW. 1991. The plant vigour hypothesis \& herbivore attack. Oikos 244-251.

407

408 Riotte-Lambert L, Benhamou S, Chamaille-Jammes S. 2013. Periodicity analysis of movement 409 recursions. Journal of Theoretical Biology 317: 238-243.

410

411 Williams NM, Thomson JD. 1998. Trapline foraging by bumble bees: III. Temporal patterns of 412 visitation and foraging success at single plants. Behavioural Ecology 9: 612-621.

413

414 Winnie JA, Cross P, Getz W. 2008. Habitat quality and heterogeneity influence distribution and 415 behaviour in African buffalo (Syncerus caffer). Ecology 89: 1457-146 
4198.

PeerJ reviewing PDF | (2015:03:4221:1:0:NEW 22 May 2015) 
429

430

431

432

433 


\section{1}

Map of study site

The Lower Kinabatangan Wildlife Sanctuary, Sabah, Malaysia (English et al., 2014b).

(Adapted from Clouded Leopard Project, Sabah www.cloudedleopard.org).

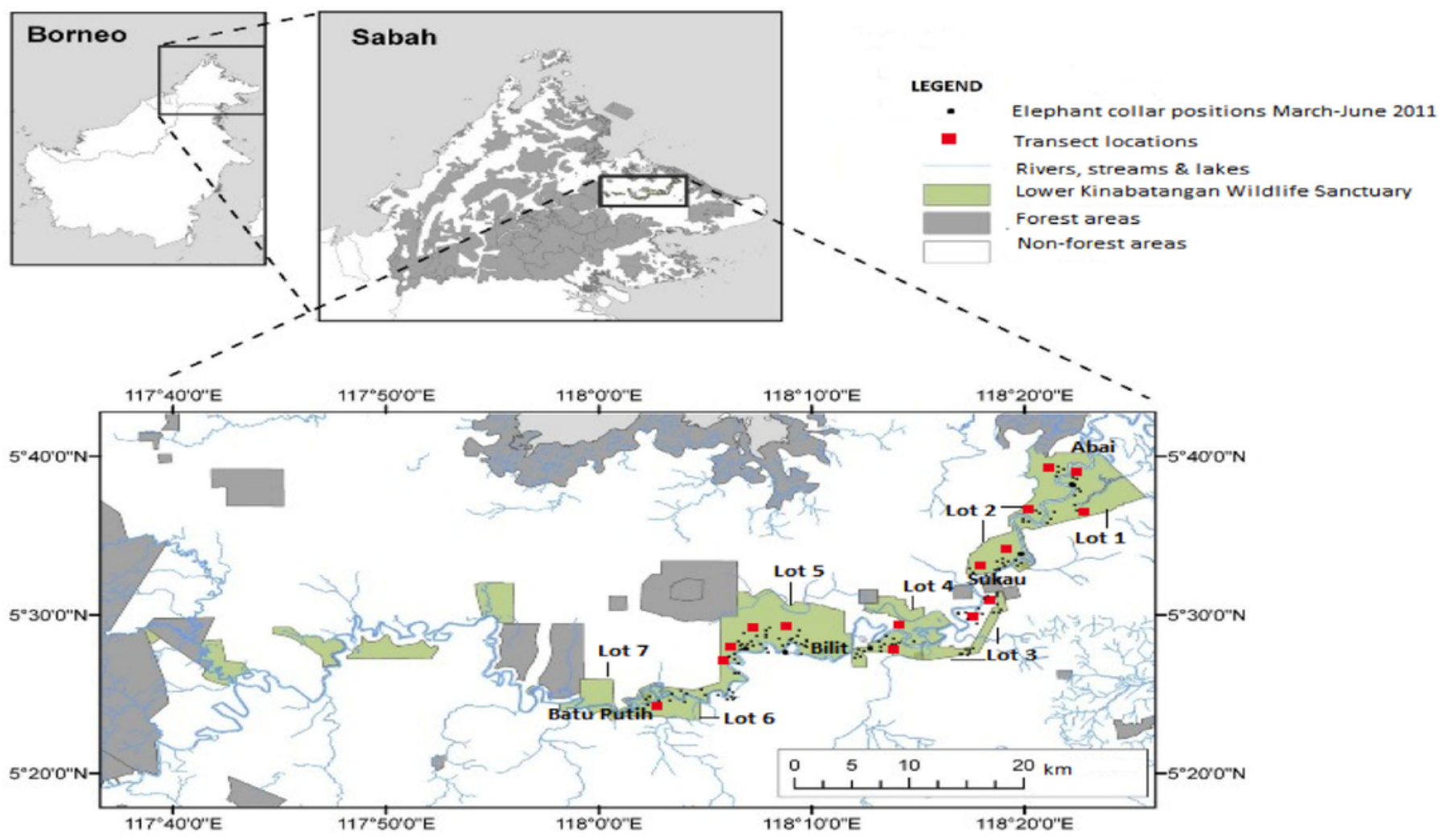


Typological examples of plant growth forms

Examples of plants selected by elephants in LKWS showing plant growth forms and their recovery. White arrows indicate portions of the plant eaten by elephant and black arrows indicate recovery growth.

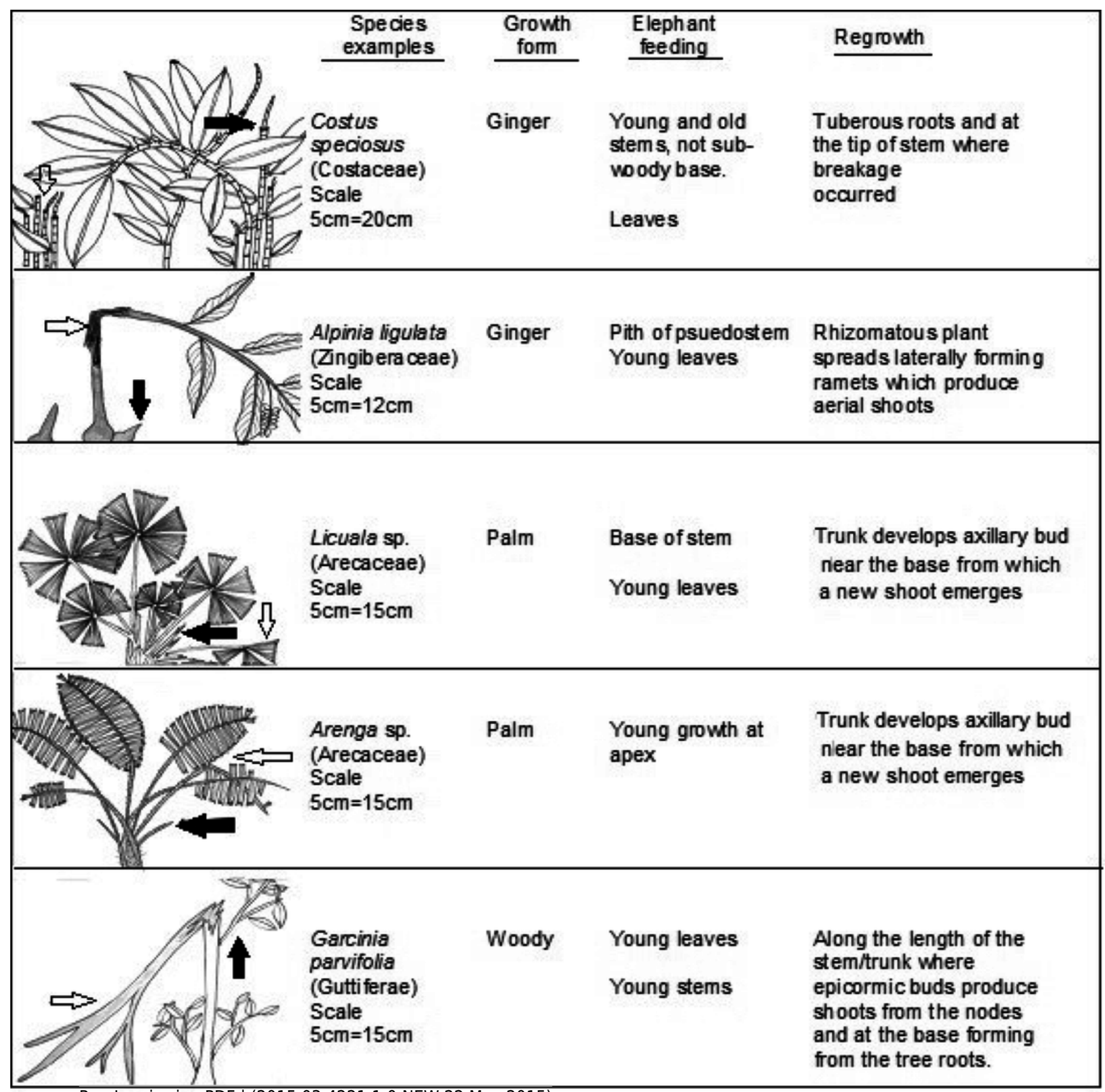


3

Plant recursion and plant mortality

A) The percentage of plants along transects re-browsed by elephants. Nu number of plants of each plant group eaten by elephants at the first visit $\mathbf{N r}$ number of plants of each plant group that were re-browsed B) Plant mortality within plant growth forms. De number of plants that died. 


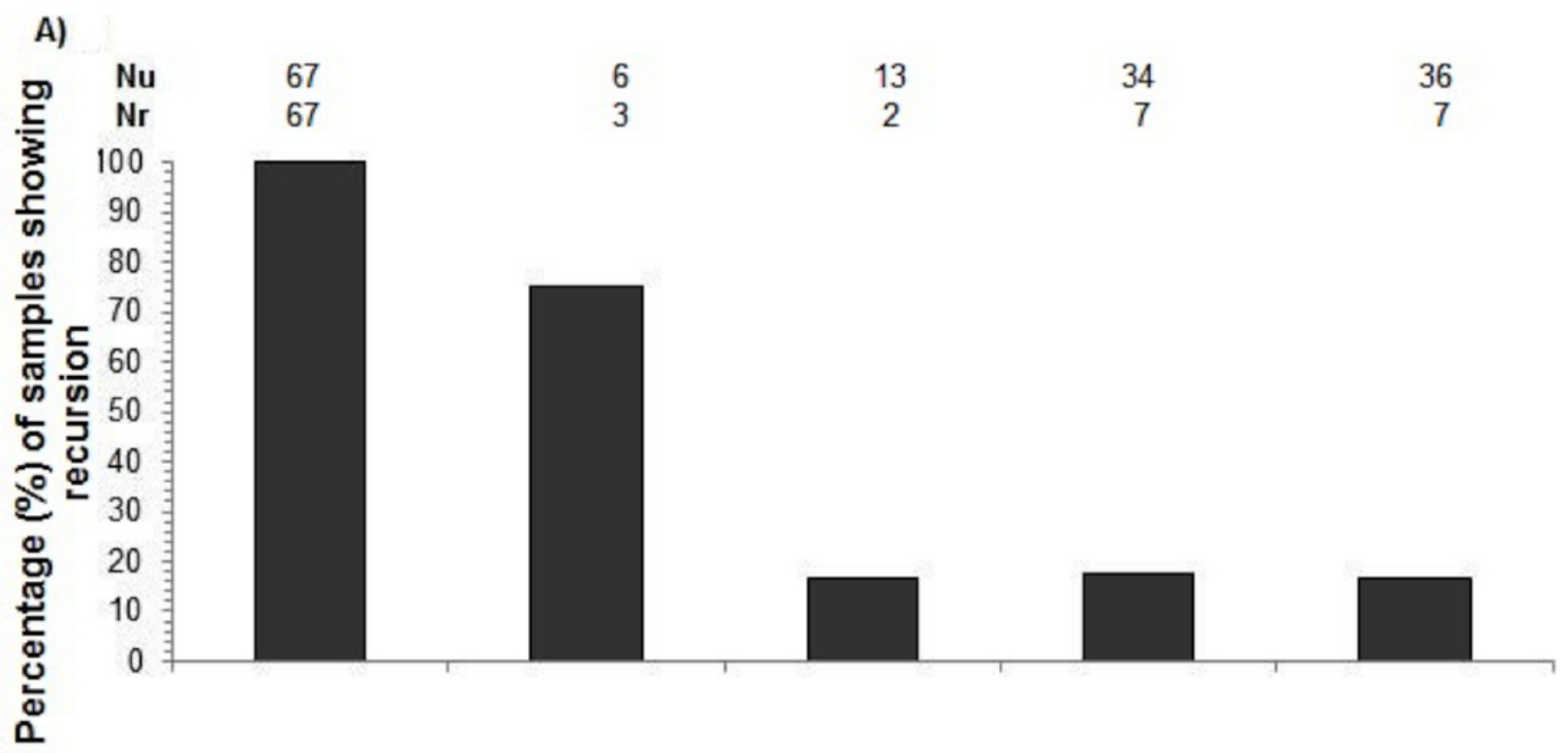

B)

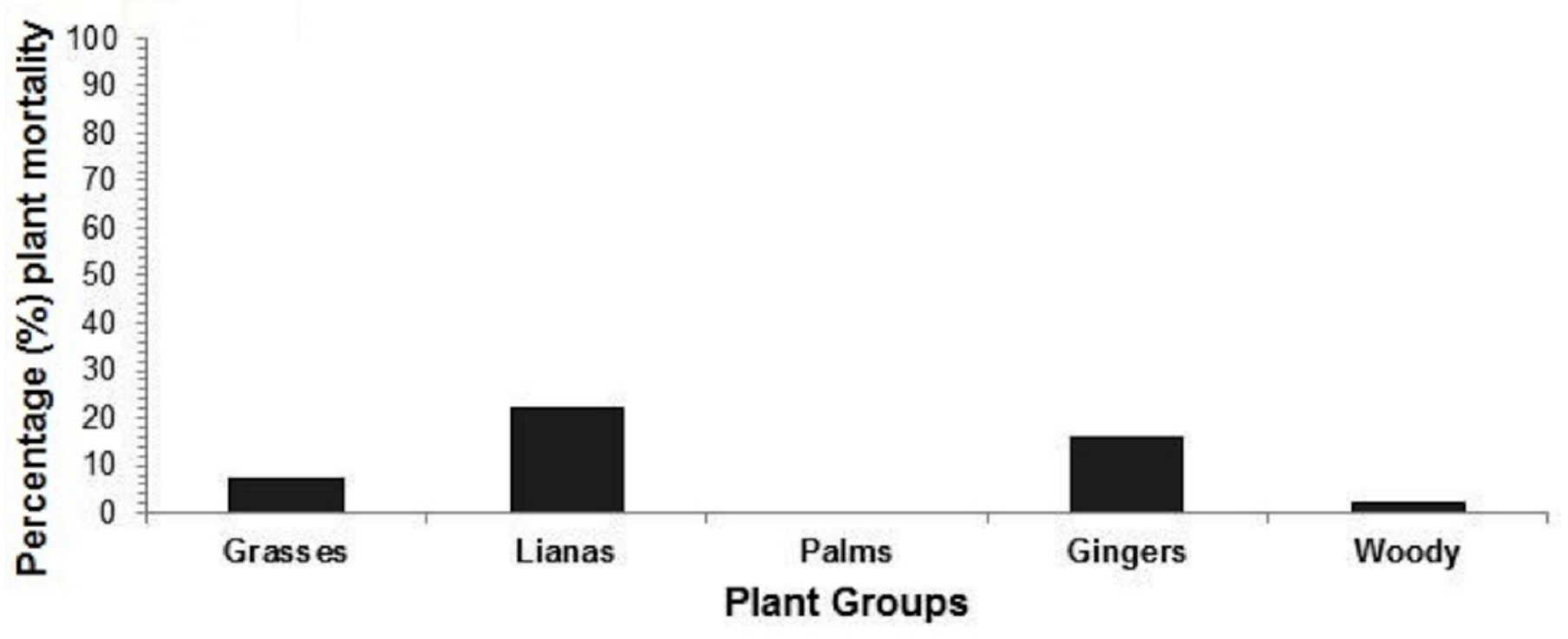




\section{4}

Recursion to grasses

Recursion to grasses showing the average length of the grass stem when initially fed on (shaded bar) and the average total length of new shoots per month until recursion occurred, for two grass species A) Phragmites karka and B) Dinochloa scabrida. Standard error bars represent \pm 1 standard deviation of the sample distribution. Recovery has occurred when the black bar is the same length as the white bar. 


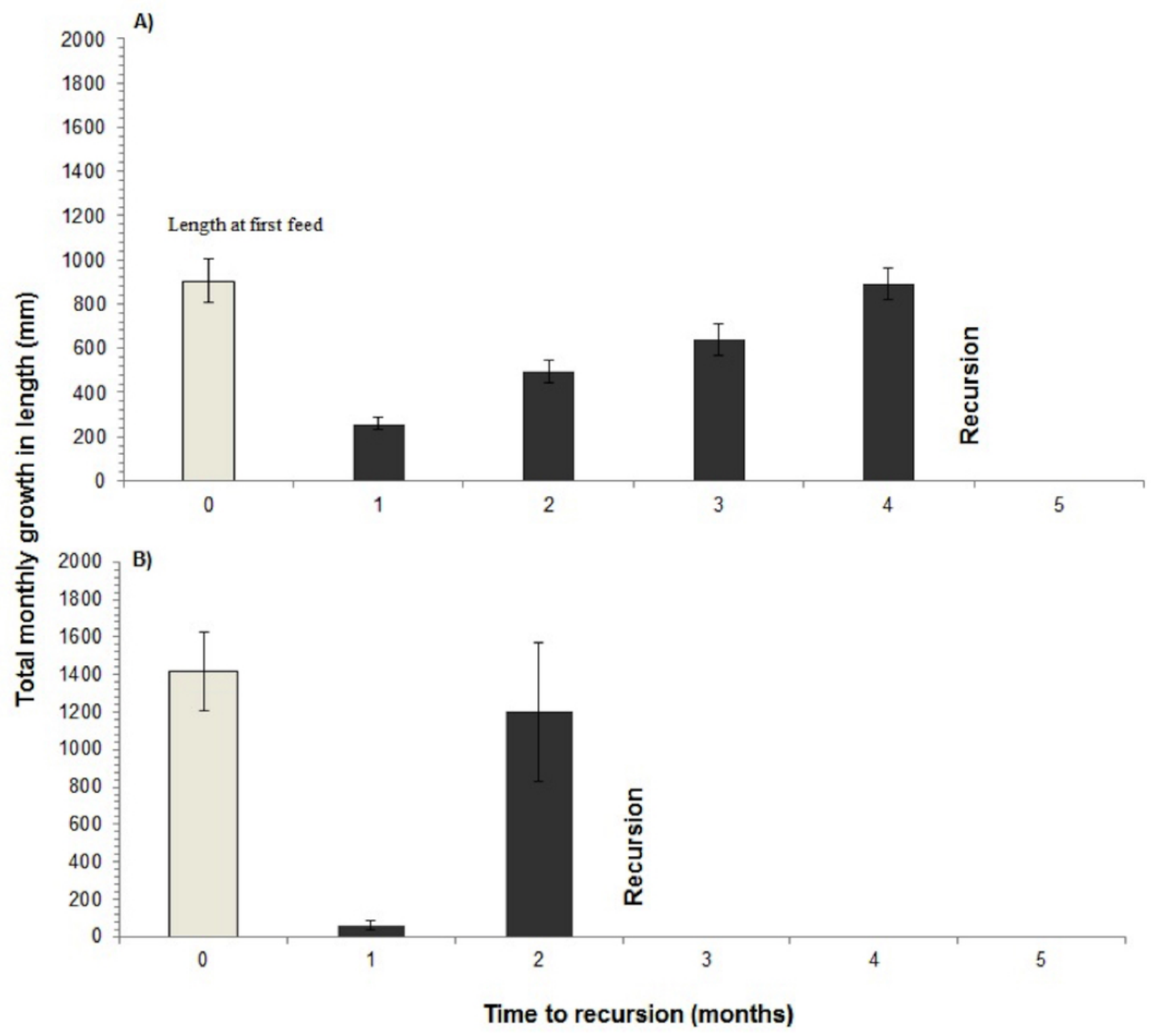




\section{5}

Time to recursion-Time to recovery

Time to recursion (months) minus Time to recovery (months) averages for each plant growth form. Numbers above bars represent the number of species within each growth form that received recursion. A positive value on the $y$-axis means that recursion occurred faster than plant recovery and a negative value means recursion occurred before plant recovery.

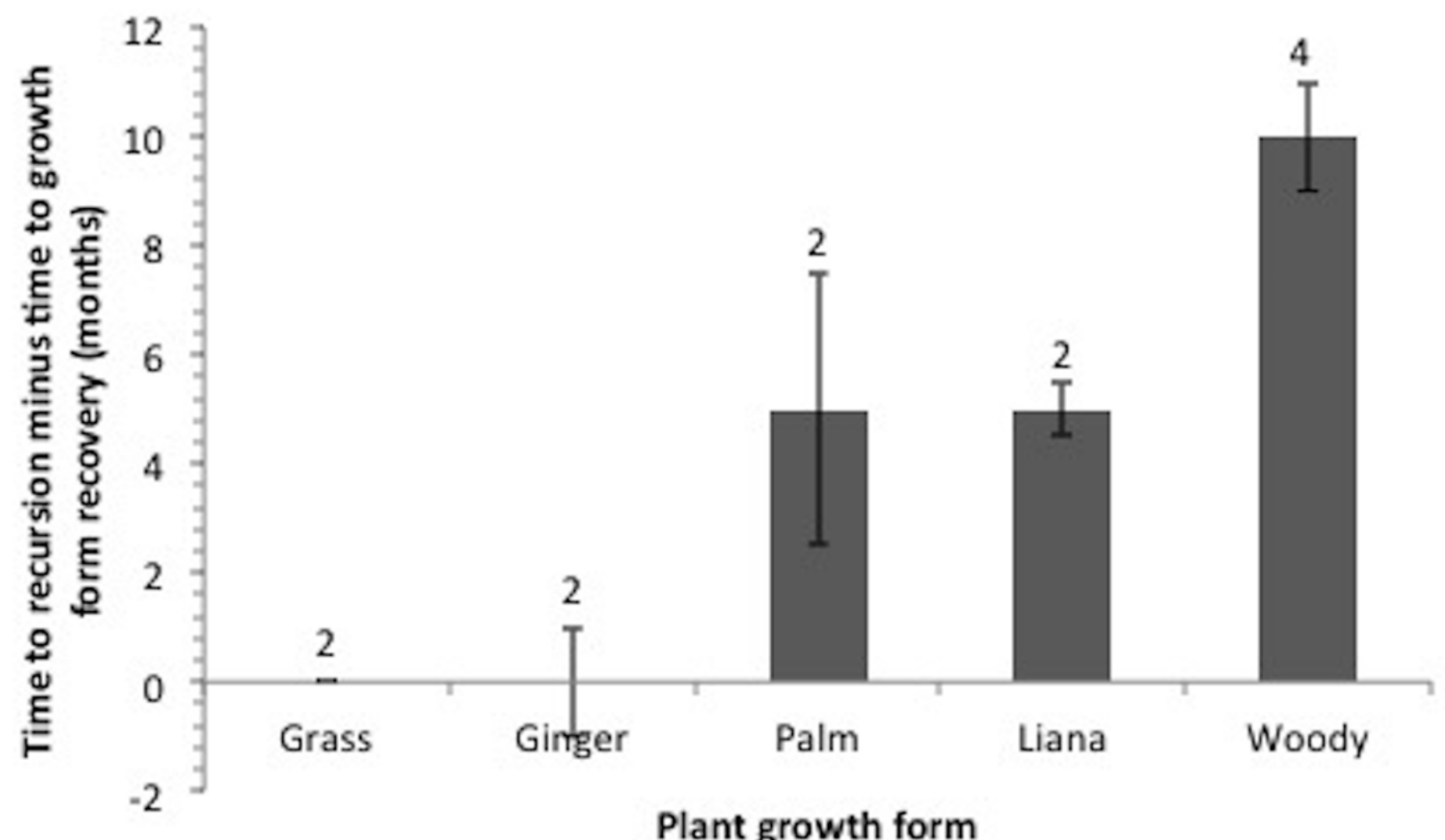




\section{Table $\mathbf{1}$ (on next page)}

Elephant food plants and recursion

Plant genus/species eaten by elephants and those re-browsed at recursion during the 9month study period. The number of plants eaten, number returned to, average time to plant species recovery and time to re-browsing at recursion are shown. * represents plant species that did not receive recursion. 


\begin{tabular}{|c|c|c|c|c|c|c|}
\hline Growth form & Family & Genus/species & Plant eaten & Plant recursion & $\begin{array}{l}\text { Average recovery time range } \\
\text { (months) }\end{array}$ & $\begin{array}{l}\text { Time to re-browsin } \\
\text { (months) }\end{array}$ \\
\hline Grass & Poaceae & Phragmites karka & 50 & 50 & $4-5$ & 5 \\
\hline Grass & Poaceae & Dinochloa scabrida & 17 & 17 & $2-3$ & 3 \\
\hline Ginger & Costaceae & Costus speciousus & 7 & 3 & $2-3$ & 5 \\
\hline Ginger & Maranthaceae & Donax canniformis & 19 & 4 & $8-9$ & 7 \\
\hline Ginger & Zingiberaceae & Alpinia ligulata & 8 & 0 & $8-11$ & $*$ \\
\hline Palm & Arecaceae & Calamus caesius & 3 & 1 & $8-9$ & 4 \\
\hline Palm & Arecaceae & Arenga sp. & 4 & 1 & $7-9$ & 4 \\
\hline Palm & Arecaceae & Daemonorops sp. & 3 & 0 & $11-14$ & $*$ \\
\hline Palm & Arecaceae & Licuala sp. & 3 & 0 & $10-15$ & $*$ \\
\hline Liana & Leguminosae & Spatholobus sp. & 3 & 1 & $3-4$ & 4 \\
\hline Liana & Leguminosae & Fordia sp. & 3 & 2 & $8-12$ & 2 \\
\hline Woody & Guttiferae & Garcinia parvifolia & 5 & 1 & $12-20$ & 3 \\
\hline Woody & Euphorbiaceae & Claoxylon sp. & 2 & 2 & $9-16$ & 5 \\
\hline Woody & Dilleniaceae & Dillenia sp. & 3 & 0 & $10-15$ & $*$ \\
\hline Woody & Cornaceae & Alangium sp. & 2 & 0 & $2-4$ & $*$ \\
\hline Woody & Sapindaceae & Lepisanthes sp. & 4 & 3 & $12-14$ & 2 \\
\hline Woody & Melastomataceae & Memecylon panniculum & 2 & 1 & $5-6$ & 2 \\
\hline Woody & Myrtaceae & Szygium sp. & 2 & 0 & $12-14$ & $*$ \\
\hline Woody & Rubiaceae & Gardenia elata & 2 & 0 & $10-12$ & $*$ \\
\hline Woody & Hypericaceae & Cratoxylum sp. & 1 & 0 & 11 & $*$ \\
\hline Woody & Phyllanthaceae & Bridelia sp. & 1 & 0 & 12 & $*$ \\
\hline Woody & Euphorbiaceae & Mallotus sp. & 1 & 0 & 14 & $*$ \\
\hline Woody & Rutaceae & Clausena excavata & 1 & 0 & 2 & $*$ \\
\hline Woody & Euphorbiaceae & Macaranga sp. & 2 & 0 & $6-8$ & $*$ \\
\hline
\end{tabular}




\begin{tabular}{lllllll} 
Woody & Euphorbiaceae & Paracroton $\mathrm{sp}$. & 2 & 0 & $12-15$ & $*$ \\
Woody & Meliaceae & Dysoxylum $\mathrm{sp}$. & 1 & 0 & 3 & $*$ \\
Woody & Lamiaceae & Callicarpa $\mathrm{sp}$. & 2 & 0 & 12 & $*$ \\
Woody & Leeaceae & Indica sp. & 1 & 0 & 16 & $*$ \\
Woody & Phyllanthaceae & Antidesma thwaites & 1 & 0 & 14 & $*$ \\
Woody & Apocynaceae & Rauvolfia sp. & 1 & 0 & $*$ \\
\hline
\end{tabular}


Table 2 (on next page)

Multimodel inference and selection

Four models ranked in order of AIC weights where recovery time (months) is the fixed-effect and plant growth form and site are random-effects, the response variable is time to recursion (months). 


\section{PeerJ Reviewing Manuscript}

\begin{tabular}{cclccccc}
\hline Model & Fixed Effects & Random Effects & n & K & AICc & AIC & $\boldsymbol{0}$ \\
\hline 1 & Recovery Time & Growth Form \& SiteID & 146 & 4 & 561.9 & 0 & $\mathbf{0 . 6 3 0 0}$ \\
2 & (base model) & Growth Form \& SiteID & 146 & 3 & 563.2 & 1.3 & $\mathbf{0 . 3 3 0 0}$ \\
3 & Recovery Time & Growth Form & 146 & 3 & 567.1 & 5.2 & 0.0500 \\
4 & Recovery Time & SiteID & 146 & 3 & 612.1 & 50.2 & 0.0000 \\
\hline
\end{tabular}

